\title{
Synthesis of biodegradable thermoplastic elastomers (BTPE) based on $\varepsilon$-caprolactone
}

\author{
V. T. Lipik1, L. K. Widjaja1, S. S. Liow ${ }^{1}$, S. S. Venkatraman ${ }^{1}$, M. J. M. Abadie ${ }^{* 1,2}$ \\ ${ }^{1}$ School of Materials Science \& Engineering, Block N4.1, Level 1, Room \# 15, 50 Nanyang Avenue, Nanyang \\ Technological University, Singapore 639798, Singapore \\ 2Laboratory of Polymer Science \& Advanced Organic Materials LEMP/MAO, CC 021, Université Montpellier II, \\ Sciences et Techniques du Languedoc, Place Eugène Bataillon, 34095 Montpellier cedex 05, France
}

Received 20 August 2009; accepted in revised form 18 October 2009

\begin{abstract}
Aiming to mimic blood vessels, biodegradable thermoplastic elastomer (BTPE) is designed to be elastic, flexible and tough. A series of biodegradable triblock copolymers and poly(ester-urethanes) (PEU) based on $\varepsilon$-caprolactone have been synthesized and studied. The crystallinity of the poly( $\varepsilon$-caprolactone) used as soft segment has been disrupted by incorporating either L-lactide (L-LA) units or trimethylene carbonate (TMC) units. Our studies suggest that soft segment composition does affect the mechanical properties significantly.
\end{abstract}

Keywords: polymer synthesis, tailor-made polymers, biodegradable polymers, mechanical properties

\section{Introduction}

Although thermoplastic elastomers (TPE) have been known since 1970s by the trade name KRA$\mathrm{TON}^{\circledR}$, intensive research for biodegradable TPE just started recently and there are not many commercial elastomeric biodegradable materials in the market today. Biodegradable thermoplastic elastomers with elastomeric mechanical properties, remoldability, wide range of biodegradation rates, and cytocompatibility are always desired for numerous biomedical applications, most predominantly as cardiovascular assist devices, controlled drug delivery and tissue engineering scaffolds $[1,2]$.

In last decade, researches on biodegradable copolymers $[3,4]$ and polyurethanes $[5,6]$ have robustly grown because they may offer good elasticity and unique properties that favor the development of new biomedical materials. However, one of the potential drawbacks of these elastomers is that their rubbery property is restricted by crystalline struc- tures in soft segment. Conventional biomedical copolymers or polyurethanes under studies are made of polycaprolactone (PCL) and/or poly(ethylene glycol) diol as soft segment [6,7], these semicrystalline chains in soft segment give rise to lower chain mobility.

In this project, biodegradable TPE having soft block and hard block are being prepared. Two alternatives are investigated where the soft segment is prepared by using coordinated anionic ring opening polymerization (CAROP) of $\varepsilon$-caprolactone mixed with L-Lactide (L-LA) or trimethylene carbonate (TMC), with stannous octoate as biocompatible FDA approved catalyst [4] and diol as the initiator or by a combination of CAROP of $\varepsilon$-caprolactone mixed with L-LA and polycondensation reactions. The first option is to copolymerize the hard segment with L-LA to get a tri-block copolymer whereas the second optional is to polycondensate the dihydroxy poly( $\varepsilon$-caprolactone-co-LLA) with 
diisocyanate to make a multiblock poly(ester-urethane). For the initial stages of this project, attempts were made at synthesizing the soft block of TPE using random copolymer of $\varepsilon$-caprolactone and L-LA or TMC with various compositions. The target is to make the soft block to be completely amorphous or at least having minimum crystallinity, thus giving the triblock a large elongation. Then this soft block will be coupled either with the hard block made of L-LA or condensed with diisocyanate, which will act as an anchor point to give the elastic property of the TPE.

\section{Experimental section}

\subsection{Materials}

Epsilon-caprolactone (CL) monomer (99\%) was purchased from Fluka, Singapore, and used without further purification. L-lactide (L-LA) was obtained from Sigma Aldrich, Singapore. It was freshly purified by recrystallization in ethyl acetate, dried in $40^{\circ} \mathrm{C}$ vacuum oven for 24 hours before every synthesis. Trimethylene carbonate (TMC) was purchased from Boehringer Ingelheim. The initiator, 2,2-dimethyl 1,3-propanediol (purum, >99.0\%) was purchased from Fluka, Singapore. It was dried in $40^{\circ} \mathrm{C}$ vacuum oven for 24 hours for water elimi- nation prior to use because it absorbs moisture from the air easily. The catalyst, tin (II) 2-ethylhexanoate $\left(\mathrm{SnOct}_{2}\right)$ was purchased from Sigma Aldrich, Singapore. It was stored over molecular sieves $(0.4 \mathrm{~nm})$. Anhydrous toluene (99.8\%), which was obtained from Sigma Aldrich, Singapore, was used as solvent in the copolymerization reaction. It was used as received. Ethyl acetate, which was obtained from Aik Moh Chemical, Singapore, was stored over molecular sieves $(0.4 \mathrm{~nm})$.

In polycondensation reaction, the hard segment, hexamethylene diisocyanate, HMDI, (puriss, $>99.0 \%$ ) was purchased from Fluka, Singapore, and used as received. The chain extender, 1,4butanediol (99\%) was obtained from Alfa Aesar, was stored over molecular sieves $(0.4 \mathrm{~nm})$.

\subsection{Synthesis}

ABA triblock copolymers, where A is a PLLA hard segment and $B$ is the soft segment made of random copolymer of $\varepsilon$-CL and L-LA or TMC were prepared by one-step living coordinated anionic ringopening polymerization. The syntheses were done in a two necks round bottom flask $(100 \mathrm{ml})$ equipped with thermometer, condenser and magnetic stirrer. The flask was purged with nitrogen,

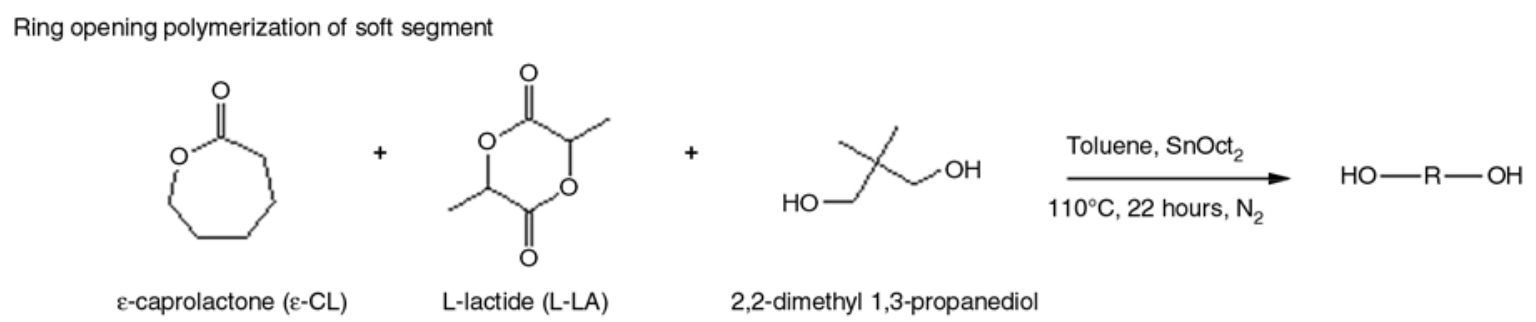

\section{Polycondensation of polyurethane}

$1 \mathrm{HO}-\mathrm{R}-\mathrm{OH}+2 \mathrm{O}=\mathrm{C}=\mathrm{N}-\left(\mathrm{C}_{2}\right)_{6}-\mathrm{N}=\mathrm{C}=\mathrm{O}$

Hexamethylene diisocyanate (HMDI)

Polyurethane chain extension

$\mathrm{I}=\mathrm{O}=\mathrm{N}-\mathrm{R}^{\prime}-\mathrm{N}=\mathrm{C}=\mathrm{O}+1 \mathrm{HO}-\mathrm{R}^{\prime \prime}-\mathrm{OH}$

1,4-butanediol (BD)

Notes:

$\mathrm{R}=$ random copolymer of $\varepsilon-\mathrm{CL}$ and $\mathrm{L}-\mathrm{LA}$

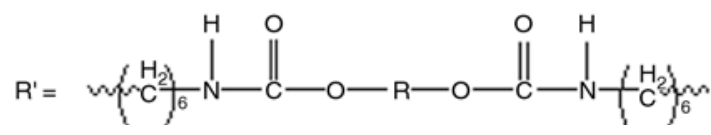

Figure 1. PEU synthesis routes
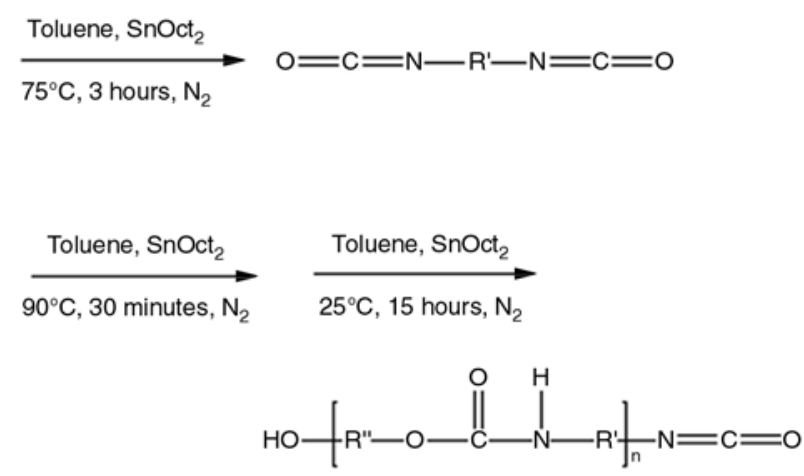
vacuumed twice and after that was kept under the nitrogen atmosphere. A mixture of $\varepsilon$-capolactone and L-LA or TMC monomers were added to the toluene and then a certain amount of propane-diol was added according to the desired degree of polymerization, lastly $\mathrm{SnOct}_{2}$ as catalyst was added to the mixture and the flask was immersed into silicone oil bath with temperature of $140^{\circ} \mathrm{C}$ for 24 hours. After that, a defined quantity of L-LA was added to the flask and the mixture was kept another 24 hours. Polymer was precipitated in methanol and dried under vacuum for 3 days.

Multiblock poly(ester-urethanes) were prepared by polycondensation of soft segment with HMDI and chain extension by 1,4-butanediol. The polyurethanes used in this study were synthesized by two-step method in nitrogen atmosphere. Briefly, the stoichiometry of the reaction was set to $2: 1: 1$ hard segment (HMDI): soft segment (HO-PCL-coPLLA-OH): chain extender (BD). Simultaneously with the soft segment polymerization, HMDI was injected into the soft segment solution at $75^{\circ} \mathrm{C}$. After the mixture was allowed to react for 3 hours, the mixture temperature was raised to $90^{\circ} \mathrm{C}$ while 1,4-butanediol was added dropwise into the flask. This temperature was maintained for 30 minutes under vigorous stirring (>1000 rpm). The mixture was then cooled down to room temperature while the chain-linking reaction was continued for another 15 hours. After the reaction was completed, the product was poured into a Teflon ${ }^{\circledR}$ dish. It was air dried in hood at room temperature for 24 hours, and vacuum dried at $55^{\circ} \mathrm{C}$ for 48 hours. Detailed chemical schemes are shown in Figure 1.

\subsection{Measurement}

The molar masses data were obtained by size exclusion chromatography (Agilent 1100 Series) using chloroform as the eluent at a flow rate of $1 \mathrm{ml} \cdot \mathrm{min}^{-1}$. Polystyrene standards were used to calibrate the molar mass. Thermal analysis was carried out on a TA Instruments Model Q10 DSC machine. Tensile test was carried out using the INSTRON 5848 microtester and its software INSTRON Bluehill. The dog-bone shape specimens were pulled in the vertical direction at a rate of $50 \mathrm{~mm} / \mathrm{min}$ and a minimum of 5 specimens per sample were tested. For cyclic tests, which were also performed at room temperature, one sample was tested. The dog shape bone sample was pulled in vertical direction with the rate $10 \mathrm{~mm}$ per minute. The rate of recovery was the same.

\section{Results and discussions}

\subsection{Triblocks based on $\varepsilon$-caprolactone $\&$ L-lactide}

Due to high crystallinity of the soft segment, triblock PLLA-b-(PCL-co-PLLA)-b-PLLA having a molar mass of $5000 \mathrm{Da} / 5000 \mathrm{Da} / 5000 \mathrm{Da}$, represented as 5-5-5 kDa, has demonstrated a poor elongation $5 \%$ at maximum load.

A series of soft segments as random copolymers containing a variable amount of lactide have been synthesized - Table 1 . The hard block is pure PLLA.

In Table 1, PCL crystallinity ( $3^{\text {rd }}$ column) is the crystallinity of the soft block whereas PLLA crystallinity ( $4^{\text {th }}$ column) is the total crystallinity of the

Table 1. Data on triblock PLLA-b-(PCL-co-PLLA)-b-PLLA

\begin{tabular}{|c|c|c|c|c|c|c|c|}
\hline $\begin{array}{c}\text { PLLA-b- } \\
\text { P(CL-LLA)-b- } \\
\text { PLLA }\end{array}$ & $\begin{array}{c}\text { \% LLA in } \\
\text { PCL } \\
{[\mathrm{mol}]}\end{array}$ & $\begin{array}{l}\text { PCL crys- } \\
\text { tallinity [\%] } \\
\text { soft block }\end{array}$ & $\begin{array}{l}\text { PLLA crys- } \\
\text { tallinity [\%] } \\
\text { copolymer }\end{array}$ & $\begin{array}{c}\mathrm{M}_{\mathbf{n}} \text { by SEC } \\
\text { [Da] } \\
\text { (DI) }\end{array}$ & $\begin{array}{c}\text { Elongation at } \\
\text { maxim load } \\
{[\mathrm{E} \%]}\end{array}$ & $\begin{array}{l}\text { Young's } \\
\text { modulus } \\
{[\mathrm{MPa}]}\end{array}$ & $\begin{array}{c}\text { Max tensile } \\
\text { stress } \\
\text { [MPa] }\end{array}$ \\
\hline $\begin{array}{c}\text { 5-10-5 } \\
\text { sample\#1 }\end{array}$ & 10 & 7.69 & 10.32 & $\begin{array}{c}13330 \\
(1.24)\end{array}$ & 22.94 & 12.01 & 4.22 \\
\hline $\begin{array}{c}5-10-5 \\
\text { sample\#2 }\end{array}$ & 25 & 0.25 & 11.55 & $\begin{array}{l}40060 \\
(1.22)\end{array}$ & 146.37 & 2.50 & 2.24 \\
\hline $\begin{array}{c}5-10-5 \\
\text { sample\#3 }\end{array}$ & 50 & 0 & 10.98 & $\begin{array}{l}26840 \\
(1.16)\end{array}$ & 35.19 & 7.03 & 2.75 \\
\hline $\begin{array}{c}5-10-5 \\
\text { sample\#4 }\end{array}$ & 75 & 0 & 20.14 & $\begin{array}{c}18939 \\
(1.32)\end{array}$ & 1.53 & 47.77 & 2.97 \\
\hline $\begin{array}{l}10-10-10 \\
\text { sample\#5 }\end{array}$ & 25 & 0 & 23.81 & $\begin{array}{c}43055 \\
(1.21)\end{array}$ & 90.77 & 5.29 & 5.62 \\
\hline $\begin{array}{l}10-10-10 \\
\text { sample\#6 }\end{array}$ & 50 & 0 & 26.93 & $\begin{array}{c}26158 \\
(1.16)\end{array}$ & 48.23 & 18.34 & 8.05 \\
\hline $\begin{array}{l}10-10-10 \\
\text { sample\#7 }\end{array}$ & 75 & 0 & 32.84 & $\begin{array}{c}24984 \\
(1.92)\end{array}$ & 0.84 & 244.00 & 2.23 \\
\hline
\end{tabular}


PLLA contained in the triblock copolymer. We observe that best mechanical properties are achieved - sample\#2, for a small amount of crytallinity of the soft block, i.e. $0.25 \%$. The crystallinity of the soft block plays a central role defining the properties of polymer.

We also observe Table 1 - samples\#5, \#6 and \#7 that the mechanical properties depend on the content of L-LA in the soft block. More L-LA in the soft block reduces PCL segment length and therefore brings hardness to the copolymer and elongation at break decreases and modulus increases.

Best elongation is obtained for the triblock PLLAb-(PCL-co-PLLA)-b-PLLA with molar mass $5 \mathrm{kDa} / 10 \mathrm{kDa} / 5 \mathrm{kDa}$ at $25 \%$ molar of lactide in the soft segment. After optimization, the best elongation obtained $-171 \%$ - Figure 2, is for molar mass $6.5 \mathrm{kDa} / 10 \mathrm{kDa} / 6.5 \mathrm{kDa}$ with $25 \%$ of lactide in the middle part of the triblock.

Shape recovery behavior has been done on the best sample - sample\#2, presented Table 1. Measured

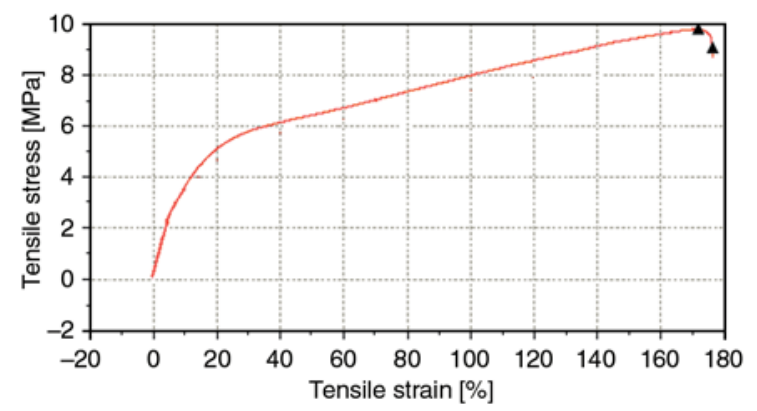

Figure 2. Instron test of copolymer triblock with the structure PLLA-b-(PCL-co-PLLA)-b-PLLA, $6.5 \mathrm{kDa} / 10 \mathrm{kDa} / 6.5 \mathrm{kDa}, 25 \%$ of L-lactide in the middle block degree of recovery was $77 \%$ after $100 \%$ of elongation.

From Table 1, we have observed that crystallinity of hard block affects elongation and modulus. To improve mechanical properties of the triblock copolymer, we have reduced the crystallinity of the hard block by incorporating $\varepsilon$-caprolactone in the PLLA at the second step of the synthesis. We have studied the influence of CL in the hard segment PLLA. Results are presented Table 2.

From Table 2, optimum value is obtained for sample\#4 where the presence of $30 \%$ of CL in the hard segment gives best elongation at break. It also shows that the presence of more than $30 \%$ of CL in the hard block gives excessive softness to the block copolymer.

Therefore if we add more $\varepsilon$-caprolactone, it brings softness. But if we add less $\varepsilon$-caprolactone, polymer contains more L-LA and becomes hard. Only one direction gives softness. At small quantity of CL in PLLA, polymers losses in elongation and cause PLLA hardness.

\subsection{Triblock based on $\varepsilon$-caprolactone and trimethylene carbonate $[8,9]$}

Various triblock copolymers with middle block made of random copolymer of $\varepsilon$-CL and TMC with molar ratio 50:50 and 75:25, and outer block of PLLA have been synthesized and studied Tables 3 and 4 . What have been varied here were the molar masses of the middle block and the outer block. It can be seen that for the middle block of

Table 2. Triblock 10-10-10 kDa, (PLLA-co-PCL)-b-(PCL-co-PLLA)-b-(PLLA-co-PCL). DI stands for polydispersity index

\begin{tabular}{|c|c|c|c|c|c|}
\hline $\begin{array}{c}\text { Polymer } \\
\text { PLLA-PCL-PLLA } \\
\text { [kDa] }\end{array}$ & $\begin{array}{c}\text { \%LLA in } \\
\text { PCL soft block }\end{array}$ & $\begin{array}{c}\text { \% CL in } \\
\text { PLLA hard block }\end{array}$ & $\begin{array}{c}\text { Crystallinity of PLLA } \\
\text { hard block } \\
{[\%]}\end{array}$ & $\begin{array}{c}\text { Elongation at } \\
\text { maxim load } \\
\text { [E\%] }\end{array}$ & $\begin{array}{c}\mathbf{M}_{\mathbf{n}} \text { by SEC } \\
\text { [Da] } \\
\text { (DI) }\end{array}$ \\
\hline 10-10-10 sample\#1 & 10 & 0 & 37.27 & 228 & $32536(1.17)$ \\
\hline $10-10-10$ sample\#2 & 10 & 10 & 26.22 & 271 & $30910(1.28)$ \\
\hline $10-10-10$ sample\#3 & 10 & 20 & 23.70 & 385 & $32994(1.18)$ \\
\hline $10-10-10$ sample\#4 & 10 & 30 & 11.87 & 525 & $33004(1.21)$ \\
\hline $10-10-10$ sample\#5 & 10 & 50 & 3.97 & 370 & $27504(1.29)$ \\
\hline
\end{tabular}

Table 3. Data on triblock PLLA-b-(PCL-co-PTMC)-b-PLLA, ratio TMC/E-CL = 50/50

\begin{tabular}{|c|c|c|c|c|c|c|}
\hline $\begin{array}{c}\text { PLLA-PCL-PLLA } \\
\text { [kDa] }\end{array}$ & $\begin{array}{c}\text { \% TMC } \\
\text { in PCL } \\
{[\mathbf{m o l}]}\end{array}$ & $\begin{array}{c}\text { Crystallinity } \\
{[\%]}\end{array}$ & $\begin{array}{c}\text { Elongation at } \\
\text { max load } \\
{[\mathbf{\%} \%]}\end{array}$ & $\begin{array}{c}\text { Young's } \\
\text { modulus } \\
{[\mathbf{M P a}]}\end{array}$ & $\begin{array}{c}\text { Tensile } \\
\text { strength } \\
{[\mathbf{M P a}]}\end{array}$ & $\begin{array}{c}\text { Mn by SEC } \\
\text { [Da] } \\
\text { (DI) in bracket }\end{array}$ \\
\hline 5-10-5 sample\#1 & 50 & 23 & 29 & 8.3 & 2.6 & $16470(1.63)$ \\
\hline $10-20-10$ sample\#2 & 50 & 21 & 60 & 10.8 & 4.6 \\
\hline $10-40-10$ sample\#3 & 50 & 4 & 74 & 3.5 & 1.5 \\
\hline 20-40-20 sample\#4 & 50 & 17 & 520 & 12.5 & 4.5 \\
\hline
\end{tabular}


Table 4. Data on triblock PLLA-b-(PCL-co-PTMC)-b-PLLA, ratio TMC/E-CL = 25/75

\begin{tabular}{|c|c|c|c|c|c|c|c|}
\hline $\begin{array}{c}\text { PLLA-PCL-PLLA } \\
{[\mathbf{k D a}]}\end{array}$ & $\begin{array}{c}\text { \% TMC in } \\
\text { PCL } \\
{[\mathbf{m o l}]}\end{array}$ & $\begin{array}{c}\text { Crytallinity } \\
\text { soft block } \\
{[\mathbf{\%}]}\end{array}$ & $\begin{array}{c}\text { Crystallinity } \\
\text { hard block } \\
{[\mathbf{\%}]}\end{array}$ & $\begin{array}{c}\text { Elongation at } \\
\text { maxim load } \\
{[\mathbf{E} \%]}\end{array}$ & $\begin{array}{c}\text { Young's } \\
\text { modulus } \\
{[\mathbf{M P a}]}\end{array}$ & $\begin{array}{c}\text { Tensile } \\
\text { strength } \\
{[\mathbf{M P a}]}\end{array}$ & $\begin{array}{c}\mathbf{M}_{\mathbf{n}} \text { by SEC } \\
{[\mathbf{D a}]} \\
\text { (DI) in bracket }\end{array}$ \\
\hline $20-40-20$ sample\#1 & 25 & $0.3 \%$ & $15.5 \%$ & 812 & 23.8 & 7.9 & $41580(1.24)$ \\
\hline $40-80-40$ sample\#2 & 25 & $5.8 \%$ & $14.0 \%$ & 1084 & 32.0 & 12.3 & $56110(1.40)$ \\
\hline
\end{tabular}

targeted molecular mass $10 \mathrm{kDa}$ - sample\#1, and $20 \mathrm{kDa}$ - sample\#2, the resulting middle block managed to reach the target, while for targeted $40 \mathrm{kDa}$ - samples\#3 and \#4, the result was slightly lower, probably due to the presence of trace hydroxyl group-containing impurities in the reactants and reaction system which is getting more significant as the molar mass increases.

Mechanical property wise, Table 3 shows that molar mass and the length of PLLA block played a major role. For triblock with targeted middle block of $10 \mathrm{kDa}$, increasing the L-LA content from 1.5 to 3 (with respect to CL content of 1), resulted in having a polymer which was too brittle to be made into a film. Meanwhile for middle block of $20 \mathrm{kDa}$, decreasing the L-LA content from 1.5 to 0.75 gave rise to a polymer which was too soft to be made into a film. Comparing between those with same L-LA content but different molar mass, it was observed that increasing the molar mass would result in increasing both the tensile strength and the maximum elongation of the triblock - samples\#3 and \#4 from Table 3 it can also be seen that the triblock having molar mass of $20 \mathrm{kDa} / 40 \mathrm{kDa} / 20 \mathrm{kDa}$ - sample\#4, has a good mechanical properties with elongation up to $520 \%$.

Table 4 shows two triblock copolymers with middle block of random copolymer of PCL and PTMC with $\varepsilon$-CL:TMC molar ratio of 75:25. From the previous section, it was shown that triblock with targeted molar mass of $20 \mathrm{kDa} / 40 \mathrm{kDa} / 20 \mathrm{kDa}-$ sample\#1, gave the best tensile strength and elongation, so here, the focus will be on triblock having that molar mass and higher. Preliminary study showed that the random copolymer of PCL and PTMC with molar ratio 75:25 was a semi crystalline polymer with $T_{g}$ around $-58^{\circ} \mathrm{C}$ and $T_{m}$ around $30^{\circ} \mathrm{C}$. So it was expected that the triblock had $2 T_{m}$, one from PLLA and the other from $\mathrm{P}(\varepsilon$-CL-co-TMC).

Looking at the mechanical properties, a significant increase can be observed by increasing the molar ratio of CL:TMC:CL 50:50 to 25:75 for molar mass

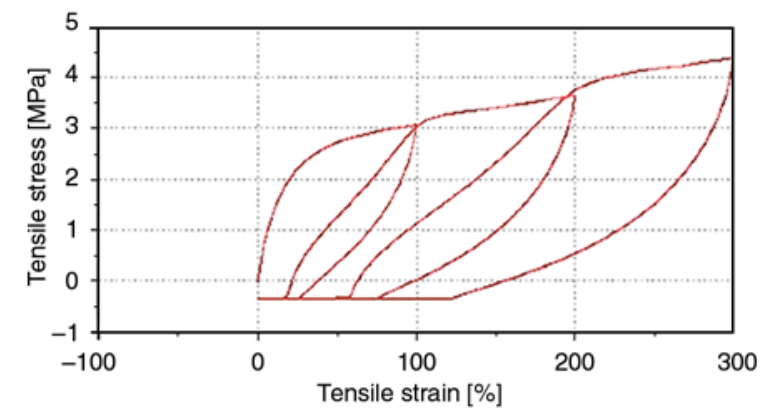

Figure 3. Cyclic test of triblock PLLA-b-(PCL-coPTMC)-b-PLLA, ratio TMC/ $\varepsilon-C L=25 / 75$ at room temperature

of $20 \mathrm{kDa} / 40 \mathrm{kDa} / 20 \mathrm{kDa}$ - sample\#1, Table 4 (compare Tables 3 and 4). An attempt to synthesize higher molar mass of 40k-80-40k - sample\#2, Table 4, resulted in further increase in tensile strength and elongation, although the actual molar mass of the polymer was far below the targeted. This might be due to transesterification reactions which were caused by catalyst during the propagation reactions. Nevertheless, a polymer with a good mechanical property having tensile strength of $12.3 \mathrm{MPa}$ and elongation of $1084 \%$ managed to be achieved.

Shape recovery behavior has been done on the best sample - sample\#2, presented Table 4. Measured degree of recovery - Figure 3, according to the cyclic test was $82.1 \%$ after $100 \%$ of elongation and $70.5 \%$ after $200 \%$ of elongation. After the $300 \%$ elongation, the sample was taken out from the Instron machine and after 10 minutes the final measured recovery was $89.7 \%$.

\subsection{Multiblock poly(ester-urethane) elastomers PEU [10]}

In a first step hydroxyl-terminated random copolymers of polycaprolactone and poly(L-lactide) were synthesized by ring opening polymerization, which is initiated by 2,2-dimethyl 1,3-propanediol. The molar fraction of L-LA in the soft segment is in mole 75, 50 and 25\% respectively. Characteristics of soft segment were shown in Table 5. 
Table 5. Characteristics of soft segment

\begin{tabular}{|c|c|c|c|}
\hline $\begin{array}{c}\text { Sample } \\
\text { ID }\end{array}$ & $\begin{array}{c}\text { \%LLA in PCL } \\
\text { [mole] }\end{array}$ & $\begin{array}{c}\mathbf{M}_{\mathbf{n}} \text { by SEC } \\
{[\mathbf{D a}]}\end{array}$ & DI \\
\hline PCL25 & 75 & 9410 & 1.31 \\
\hline PCL50 & 50 & 11050 & 1.29 \\
\hline PCL75 & 25 & 12070 & 1.30 \\
\hline
\end{tabular}

From hydroxyl-terminated random copolymer of PCL and PLLA serving as soft segment - Table 5, a series of degradable polyurethanes PEU are synthesized from HMDI and 1,4-butanediol (BD) serving as hard segment and chain extender, respectively. SEC results showed - Table 5. PEU molar masses were ranged from 48 to $57 \mathrm{kDa}$. Soft segment composition may not affect molar weights of PEU since the molar masses obtained were similar. Narrow molar mass distribution was observed suggesting a balance stoichiometry in the synthesis.

$T_{g}$ was slightly higher than their respective soft segments. All $T_{g}$ s were below room temperature, suggesting that all PEU have elastomeric characteristics at body temperature. No melting peak was detected due to absence of crystalline structures in these polyurethanes. Table 6 showed the bulk properties of PEU.

Tensile stress-strain curves measured for all the PEU, and commercial non-biodegradable thermoplastic elastomers (TPE) such as SBS and ether-

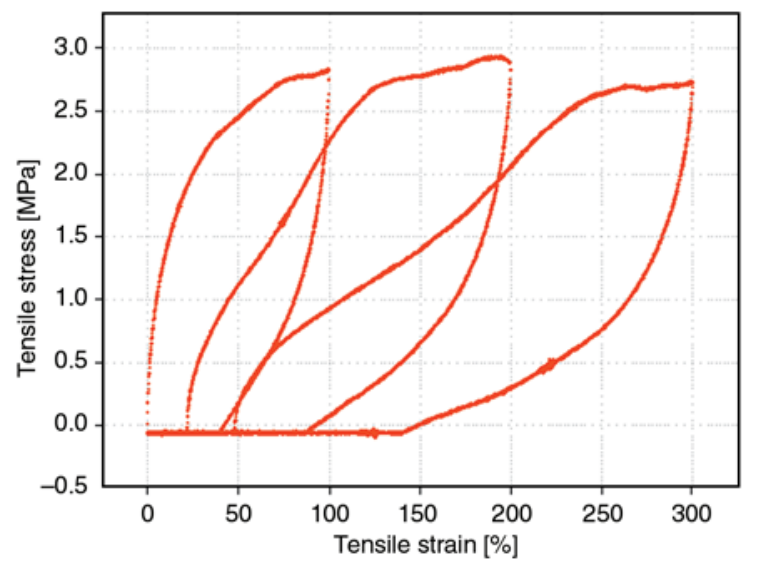

Figure 4. Cyclic test of PUCL25 at room temperature, with rate of deformation $100 \%$ per minute based PU were studied. Comparing among PEU, higher lactide content (PUCL25 - sample\#1) results in significant increase in strain at break: e.g. increase lactide content 3 times from 25 to $75 \mathrm{~mol} \%$, strain at break increased 7.1 times from 114 to $811 \%$. We also observe for this sample a strain recovery from cyclic test - Figure 4, of $77.9 \%$. In contrast to commercial SBS and etherbased PU, PUCL25 showed better tensile properties but similar elongation, $738 \%$ for SBS and $843 \%$ for ether PU.

On the other hand, PUCL50 - sample\#2 and PUCL75 - sample\#3 showed strain in the range of human vein and artery (150-200\% strain at break). Despite of the good mechanical properties, toxicity of PEU that based on HMDI as chain coupling agent is still debatable in recent literatures. The potential toxicity could be due to the formation of HMDA during the degradation of urethane linkages [11]. As a result, our group will be focusing on the development of more biocompatible PEU that based on 1,4-diisocyanatobutane (BDI) or lysine diisocyanate (LDI) because they degrade into putrescine and lysine, respectively.

\section{Conclusions}

Triblock copolymers of $\varepsilon$-CL, TMC, and L-LA with different molar ratio and molar mass were synthesized by the ring-opening bulk copolymerization, using stannous octoate as catalyst. The molecular structures, thermal properties, as well as the mechanical properties of the triblocks changed considerably with composition.

Our study shows that increasing the moar mass will enhance the mechanical properties considerably. For the middle block poly( $\varepsilon$-caprolactone), monomers such as L-LA and TMC are good candidates to disrupt the crystallinity of the soft block; the molar ratio $\varepsilon$-CL:TMC of 75:25 gave a better mechanical properties than 50:50, most probably due to the $\varepsilon$-CL being more elastic and tough compared to TMC.

Table 6. Characteristics of multiblock poly(ester-urethane) elastomers PEU

\begin{tabular}{|c|c|c|c|c|c|c|}
\hline Sample ID & $\begin{array}{c}\text { \%L-LA } \\
\text { in PCL } \\
{[\mathbf{m o l}]}\end{array}$ & $\begin{array}{c}\text { Ultimate tensile } \\
\text { strength } \\
{[\mathbf{M P a}]}\end{array}$ & $\begin{array}{c}\text { Elongation at } \\
\text { maxim load } \\
{[\mathbf{E} \%]}\end{array}$ & $\begin{array}{c}\text { Young's } \\
\text { modulus } \\
{[\mathbf{M P a}]}\end{array}$ & $\begin{array}{c}\mathbf{M}_{\mathbf{n}} \text { by SEC } \\
{[\mathbf{D a}]} \\
\text { (DI) }\end{array}$ & $\begin{array}{c}\text { Strain recovery } \\
\text { from cyclic test } \\
{[\%]}\end{array}$ \\
\hline PUCL25 sample\#1 & 75 & 6.29 & 811 & 17.33 & $48,070(1.33)$ & 77.9 \\
\hline PUCL50 sample\#2 & 50 & 0.95 & 262 & 6.89 & $56,570(1.43)$ & Not tested \\
\hline PUCL75 sample\#3 & 25 & 0.50 & 114 & 2.40 & $51,220(1.47)$ & Not tested \\
\hline
\end{tabular}


This study also suggest that multiblock copolymers seem to have a better potentiality in term of mechanical properties that triblock copolymers as maximum strain up to $811 \%$ with strain recovery near $80 \%$ can be achieved.

\section{References}

[1] Venkatraman S., Boey F., Lao L. L.: Implanted cardiovascular polymers. Natural, synthetic and bioinspired. Progress in Polymer Science, 33, 853-874 (2008).

DOI: 10.1016/j.progpolymsci.2008.07.001

[2] Amsden B.: Curable, biodegradable elastomers: Emerging biomaterials for drug delivery and tissue engineering. Soft Matter, 3, 1335-1348 (2007). DOI: $10.1039 / \mathrm{b} 707472 \mathrm{~g}$

[3] van der Mee L., Helmich F., de Bruijn R., Vekemans J. A. J. M., Palmans A. R. A., Meijer E. W.: Investigation of lipase-catalyzed ring-opening polymerizations of lactones with various ring sizes, kinetic evaluation. Macromolecules, 39, 5021-5027 (2006).

DOI: $10.1021 / \mathrm{ma} 060668 \mathrm{j}$

[4] Wu X. S.: Synthesis and properties of biodegradable lactic/glycolic acid polymers. in 'Encyclopedic handbook of biomaterials and bioengineering' (ed.: Wise D. L.) Marcel Dekker, New York, 1015-1054 (1995).

[5] Younes H. M., Bravo-Grimaldo E., Amsden B. G.: Synthesis, characterization and in vitro degradation of a biodegradable elastomer. Biomaterials, 25, 52615269 (2004).

DOI: $\underline{10.1016 / \text { j.biomaterials.2003.12.024 }}$
[6] Tatai L., Moore T. G., Adhikari R., Malherbe F., Jayasekara R., Griffiths I.: Thermoplastic biodegradable polyurethanes: The effect of chain extender structure on properties and in-vitro degradation. Biomaterials, 28, 5407-5417 (2007).

DOI: 10.1016/j.biomaterials.2007.08.035

[7] Guan J., Sacks M. S., Beckman E. J., Wagner W. R.: Synthesis, characterization, and cytocompatibility of elastomeric, biodegradable poly(ester-urethane)ureas based on poly(caprolactone) and putrescine. Journal of Biomedical Materials Research, 61, 493-503 (2002). DOI: $10.1002 / \mathrm{jbm} .10204$

[8] Shen Y. Q., Shen Z. Q., Zhang Y. F., Huang Q. H., Shen L. F., Yuan H. Z.: Random copolymerization of $\varepsilon$-caprolactone and trimethylene carbonate with rare earth catalysts. Journal of Applied Polymer Science, 64, 2131-2139 (1997).

DOI: 10.1002/(SICI)1097-4628(19970613)64:11 $\leq 2131:$ AID-APP9>3.0.CO;2-K

[9] Zhu K. J., Hendren R. W., Jensen K., Pitt C. G.: Synthesis, properties, and biodegradation of poly(1,3trimethylene carbonate). Macromolecules, 24, 17361741 (1991). DOI: $10.1021 / \mathrm{ma} 00008 \mathrm{a} 008$

[10] Kylmä J., Seppälä J. V.: Synthesis and characterization of a biodegradable thermoplastic poly(ester-urethane) elastomer. Macromolecules, 30, 2876-2882 (1997). DOI: $\underline{10.1021 / \mathrm{ma} 961569 \mathrm{~g}}$

[11] Tuominen J., Kylmä J., Kapanen A., Venelampi O., Itävaara M., Seppälä J.: Biodegradation of lactic acid based polymers under controlled composting conditions and evaluation of the ecotoxicological impact. Biomacromolecules, 3, 445-455 (2002). DOI: $\underline{10.1021 / \mathrm{bm} 0101522}$ 